\title{
A study of solvent debinding variables on Ti6Al4V green bodies
}

\author{
Mandy Seerane ${ }^{a, b,{ }^{*}}$, Hilda Chikwanda ${ }^{a}$, Walter Focke ${ }^{b}$, Ronald Machaka ${ }^{a}$ \\ ${ }^{a}$ CSIR, Pretoria \\ ${ }^{b}$ University of Pretoria \\ ”MSeerane@csir.co.za, ${ }^{a}$ HChikwanda@csir.co.za, ${ }^{b}$ walter.focke@up.ac.za, \\ arMachaka@csir.co.za
}

\begin{abstract}
Debinding is one of the most critical and time consuming stage in metal injection moulding (MIM). German and Bose (1997) reported that early debinding practice relied on thermal binder degradation, requiring up to 300 hours for complete binder removal. Today multi-stage debinding techniques are introduced cutting down the debinding time to as little as 2 hours.

This work investigates solvent debinding variables for samples made by MIM Ti6Al4V powder prior to thermal debinding. Solvent debinding is carried out in $n$-heptane. Wax and stearic acid are the target binder components being leached out from the green bodies, with wax as the major constituent in the binder formulation. Debinding is conducted at $50,55,60$ and $65^{\circ} \mathrm{C}$ for $1-4$ hours at each temperature. Weight loss measurements were done. For porosity and surface appearance, scanning electron microscope (SEM) analysis and visual inspection were done.
\end{abstract}

Samples debound at $65^{\circ} \mathrm{C}$ showed an appreciable amount of mass loss; however, surface cracks and warping were observed. A $60^{\circ} \mathrm{C}$ temperature and time of 4 hours demonstrated best results i.e. a satisfactory mass loss, absence of surface cracks and no warping. Mass loss is directly proportional to temperature and time. SEM results are discussed in the paper.

Keywords: Metal injection moulding, MIM, binder formulation, debinding, SEM

\section{Introduction}

Debinding is the removal of the binder material from the injected parts without affecting the original shape of the part, either thermally or by solvent or a combination of both [1,2]. After feedstock preparation and injection moulding to form green body, the part is introduced to debinding process whereby the binder becomes the disposable component. Debinding is one of the critical stages in MIM [3]. Failure to extract most of the binder prior and during sintering can result in component defects, such as distortion and cracking, manifesting. Insufficient binder removal, also, result in contamination from polymer decomposition during sintering. Removing the binder without the metal particles collapsing is a delicate process and can be achieved by multiple steps. Several debinding processes exist and the most popular are catalytic, solvent and thermal debinding. The goal in debinding is to remove the binder material in the shortest time possible with the least impact on the compact. Early debinding practice used to involve thermal debinding only, which 
required up to $300 \mathrm{~h}$ running to completion. Today, thermal debinding is coupled with solvent debinding and the entire process may take as little as $2 \mathrm{~h}$ depending on the binder used $[1,4]$. Solvent debinding takes advantage of the high solubility of low molecular weight binder (major constituent) components in the organic solvent. It creates channels or pores in the green body and thereby preparing the part for thermal debinding. A large amount of pores in the body allows the degraded binder (minor constituent) to easily diffuse to the surface during thermal debinding. Therefore, thermal debinding time is reduced significantly $[5,6]$.

Developing a scientific understanding of debinding processes simplifies debinding. Longer debinding times are not feasible for mass production. Thomas-Vielma et. al. [6] and Liu et. al. [7] showed that coupling solvent and thermal debinding successfully reduces binder removal time and prevents defects from forming in injected parts.

This paper focuses on the investigation of solvent debinding parameters and the determination of optimal conditions for this process.

\section{Experimental approach}

\section{Materials}

The powder used is Ti6Al4V. Table 1 shows the powder characteristics. Loading: 65 vol.\%. The binder consisted of 55 vol.\% paraffin wax (PW), 35 vol.\% low density polyethylene (LDPE) and 10 vol.\% stearic acid (SA).

Table 1: Powder characteristics

\begin{tabular}{|c|c|c|c|c|c|c|c|}
\hline Powder & $\begin{array}{l}\text { Size } \\
\text { distribution }\end{array}$ & $\mathbf{D}_{50}[\mu \mathrm{m}]$ & $\mathbf{D}_{90}[\mu \mathrm{m}]$ & $\mathbf{D}_{10}[\mu \mathrm{m}]$ & $\overline{\mathbf{S}_{\mathbf{w}}}$ & $\begin{array}{l}\text { Density } \\
{\left[\mathrm{g} / \mathrm{cm}^{3}\right]}\end{array}$ & Shape \\
\hline Ti6Al4V & $-25+6$ & 13.4 & 24.0 & 6.41 & 4.43 & 4.43 & Spherical \\
\hline \multicolumn{8}{|c|}{${ }^{*} \mathrm{~S}_{\mathrm{w}}($ distribution slope parameter $)=2.56 / \log \left(\mathrm{D}_{90} / \mathrm{D}_{10}\right)$} \\
\hline \multicolumn{8}{|c|}{$*_{-} 25+6$ denotes a distribution of particle sizes less than (-) $25 \mu \mathrm{m}$ but greater than (+) $6 \mu \mathrm{m}$} \\
\hline \multicolumn{8}{|c|}{${ }^{*} \mathrm{D}_{50}$ is the mean particle size (mean diameter) of the given particle size distribution } \\
\hline
\end{tabular}

Feedstock preparation and injection moulding

The feedstock was prepared using a Z-blade shear mixer (4223, Jones Industrial mixer) at $150{ }^{\circ} \mathrm{C}$ for 2 hours. Injection moulding was conducted using a 40 tonne ARBURG Allrounder 270U 400-70 injection moulding machine. Extensive study of feedstock characterisation was done elsewhere and, in addition to that, injection moulding parameters are presented in the cited paper [8].

Thermal analysis of the feedstock

Differential scanning calorimetry (DSC) (Q2000 V24.10) of the feedstock was conducted under nitrogen atmosphere. DSC programme: Start temperature was $10^{\circ} \mathrm{C}$ and end temperature was 200 ${ }^{\circ} \mathrm{C}$. Heating rate was $10{ }^{\circ} \mathrm{C} / \mathrm{min}$. The holding time for both starting and end temperatures was 10 minutes. Gas rate was $20 \mathrm{ml} / \mathrm{min}$. 
Solvent debinding

Green components were debound at temperatures ranging from $50-65{ }^{\circ} \mathrm{C}$ at $5{ }^{\circ} \mathrm{C}$ intervals. The debinding times were 1 to 4 hours. Solvent debinding was conducted in a $50 \mathrm{~cm}^{3} n$-heptane using a Julabo shaking water bath.

\section{Results and discussion}

DSC of the feedstock

The thermal properties of the feedstock provided a good guide to predict the injection moulding and solvent debinding temperatures. The peak melting temperatures of the feedstock range from $44.6-$ 101.8 (Fig. 1). The first peak on the upper curve (heating) depicts the melting of stearic acid and paraffin wax. The second peak on the upper curve indicated the melting of low density polyethylene. Hwang et. al. [9] indicated that the binder becomes flowable once the melting point of the highest melting binder component is exceeded.

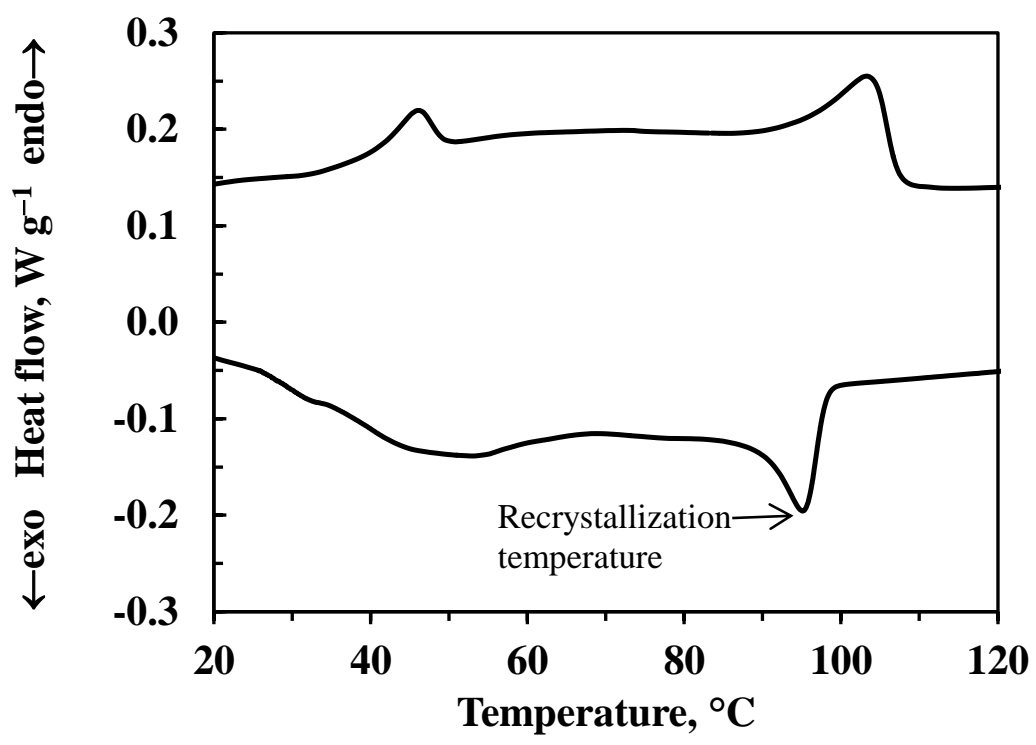

Figure 1: DSC analysis of the feedstock at the heating rate of $10^{\circ} \mathrm{C} / \mathrm{min}$

Solvent debinding

The aim of solvent debinding was to prepare the green components for thermal debinding and thus reduce the total thermal debinding time. Solvent debinding parameters were optimised using DSC results. Researchers have recently reported that MIM components start to crack once the solvent debinding temperature exceeds the peak melting points of the soluble binder components. The solvent $n$-heptane was chosen to target both paraffin wax and the stearic acid. Eventually after the partial removal of the paraffin wax and the stearic acid, a porous green part is produced. The presence of these pores or channels within the component facilitates the diffusion of low density polyethylene during thermal debinding. Fig. 2 shows the loss of the binder at various temperatures. It can be deduced that the higher the debinding temperature the faster is the loss of the binder, especially in the first hour of the process. Higher temperatures enhance binder solubility and diffusivity [10]. In addition to that, longer debinding time allow more binder loss. Also, it can be 
observed from Fig. 2 that 4 stages exist during solvent debinding. The stages are discussed in reference to Md Ani et. al. [4] work.

Stage I (0-1 hours): The loss of the binder is very fast because the binder on the surface of the component is in direct contact with the solvent (slopes relatively very high).

Stage II (1-2 hours): Debinding rate slows down (See the slopes) because the solvent must penetrate deeply into the part to dissolve and extract the binder to the surface. The diffusion of dissolved binder to the surface of the component is facilitated by capillary forces which involve liquid extraction [11].

Stage III (2-3 hours): The debinding rates increases due to enough channels created within the component which allows faster diffusion of the dissolved binder to the surface. At $65{ }^{\circ} \mathrm{C}$ the slope of the curve is the highest which explains that the rate of debinding is the highest at this stage on the curve stated. Debinding rates on curves $50{ }^{\circ} \mathrm{C}$ and $55^{\circ} \mathrm{C}$ seem to be going at the same pace (similar slopes). The debinding rate on curve $60^{\circ} \mathrm{C}$ is moderately high.

Stages IV (3-4 hours): The debinding rate slows down and the mass loss remains constant (See the slopes). At this stage, a saturation point between the binder and the solvent is reached. However, it must be noted that the equilibrium point between the latter is dependent on the solvent-component volume ratios.

There seems to be a jump of debinding rate from $55^{\circ} \mathrm{C}$ to $60{ }^{\circ} \mathrm{C}$, and this explains the sensitivity of binder solubility and diffusivity to temperature change (See Fig. 2, curves $50 / 55^{\circ} \mathrm{C}$ and $60 / 65^{\circ} \mathrm{C}$ ). Curves 50 and $55^{\circ} \mathrm{C}$, stages II - IV, the debinding rate appears to be uniformly slowing down, slopes are almost constant). On the other hand; curves 60 and $65^{\circ} \mathrm{C}$, stages II - IV, the debinding rate appears to be picking up until the end of third hour. Fig. 3 shows the general view solvent debinding mechanism, as well as the state of the binder during debinding. German and Bose [1] reported that debinding rates during solvent debinding are dependent on the molecular mobility of the dissolved binder, which is generally faster with higher temperatures and smaller solvent molecules. Fig. 4 shows cracks and warping encountered after solvent debinding. This is caused by longer debinding times, high solvent temperatures and thickness variation of the component. Longer resident time of the component in the solvent causes the insoluble binder component to swell causing crack. Higher temperature allows the binder to soften causing the green component to slump, hence, warping. In addition to that, the escape of the dissolved binder from the part is preferential, i.e. the binder prefers to leave the component from the thin surface first causing stress gradient between the thin region and the thick region of the part. Therefore, it is why warping manifests on the thin portion (Fig. 4). These surface defects were observed from the component debound at $65^{\circ} \mathrm{C}$ between 1 and 4 hours debinding time. A debinding temperature of $60{ }^{\circ} \mathrm{C}$ showed high mass loss after 4 hours without surface defects present on the component.

Mass loss of the binder $\left(\mathrm{M}_{\mathrm{b}}\right)$, which is the paraffin wax and the stearic acid, was calculated according to the following equation: 


$$
M_{b}(\%)=\frac{M_{i}-M_{f}}{M_{i}} * 100
$$

Where $M_{i}$ is the initial mass of the green body and $M_{f}$ is the mass of the green body after solvent debinding

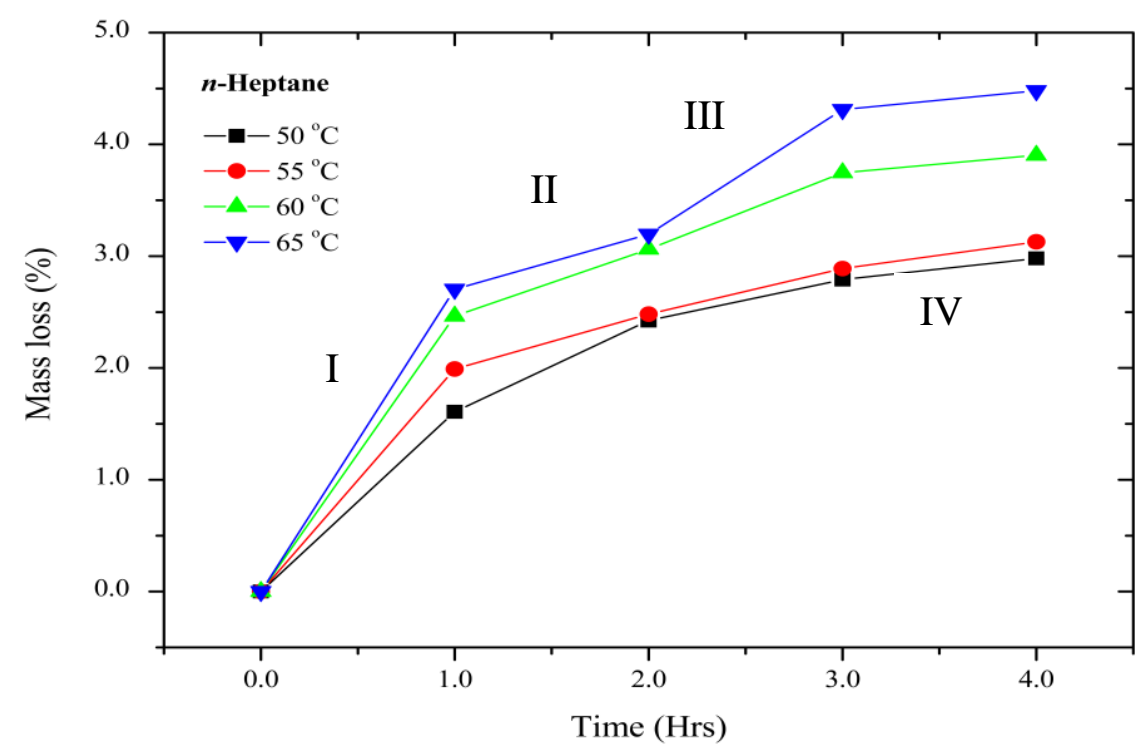

Figure 2: Mass loss of the binder from the green component at different temperatures

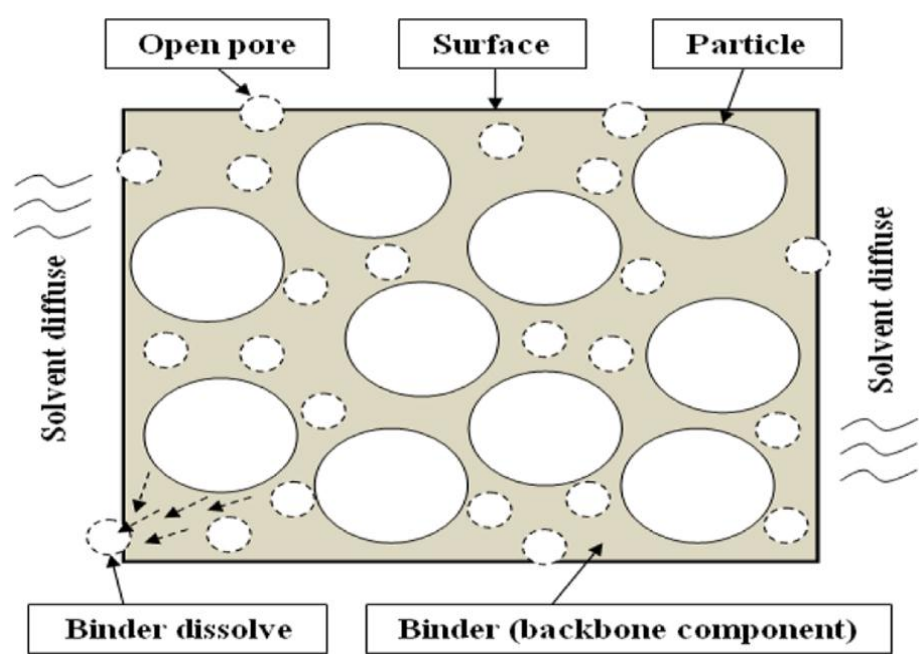

Figure 3: A schematic diagram showing the solvent-binder diffusion during solvent debinding [4]. 


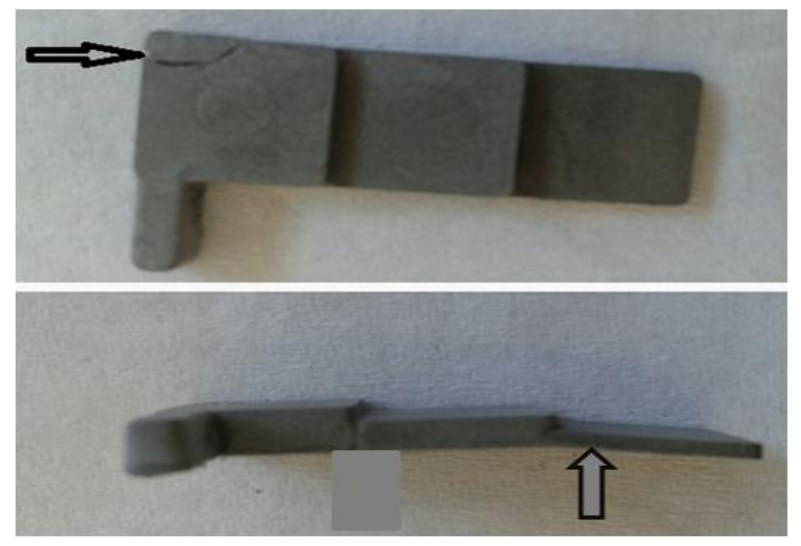

Figure 4: Surface cracks (Top) and warping (Bottom) observed on the green component after solvent debinding at $65^{\circ} \mathrm{C}$ after 4 hours

SEM micrographs show the samples before and after solvent debinding (Fig. 5). Arrow A points at the powder particles. It can be seen that the powder was evenly distributed in the binder matrix. Arrow B points at the backbone binder (LDPE), uniform polymer distribution is also observed. Arrow $\mathrm{C}$ is pointing at the binder matrix (paraffin wax and stearic acid). Arrow D points at the backbone binder (LDPE) and arrow E points at the pores generated on the specimen.
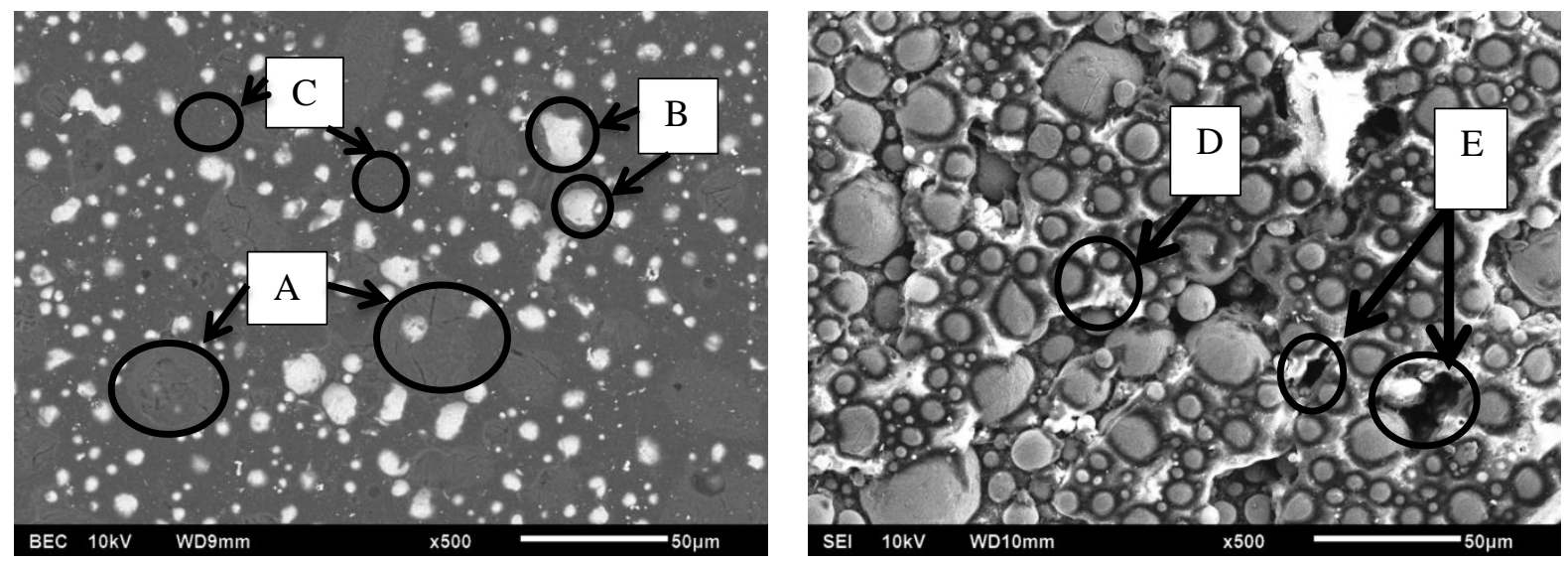

Figure 5: SEM micrographs of MIMed specimens before (left) and after (right) solvent debinding

\section{Conclusions}

Solvent debinding of the MIMed components was performed at different parameters to obtain optimal solvent debinding conditions. Temperature and resident time affects the weight loss of the MIMed components significantly. Debinding at $60{ }^{\circ} \mathrm{C}$ for 4 hours, with a solvent ( $n$-heptane) volume of $50 \mathrm{~cm}^{3}$, is considered to be the optimum solvent debinding condition due to the appreciable amount of mass loss without any risk of surface defects on the MIMed component.

\section{Acknowledgements}

The author acknowledges the CSIR for sponsoring this work and making laboratories and equipment available for this work. Acknowledgements also go to the University of Pretoria 
(Department of Chemical Engineering) for supplying equipment to run other related experiments, in particular to Mrs Isbe Van Der Westhuizen.

\section{References}

[1] R. M. German, A. Bose, Injection Molding of Metals and Ceramics, Princeton, New Jersey, MPIF, 1997.

[2] E. S. Thian, N. H. Loh, K. A. Khor, S. B. Tor, Effects of debinding parameters on powder injection molded Ti-6Al-4V/HA composite parts, Adv. Powd. Technol., 12 (2001) 361-370.

[3] B. Zhu, X. Qu, Y. Tao, Mathematical model for condensed-solvent debinding process of PIM, J. Mater. Process. Technol., 142 (2003) 487-492

[4] S. Md Ani, A. Muchtar, N. Muhamad, J. A. Ghani, Binder removal via a two-stage debinding process for ceramic injection molding parts, Ceram. Int. 40 (2014) 2819-2824

[5] M. T. Zaky, Effect of solvent debinding variables on the shape, J. Mater. Sci. 39 (2004) 3397 3402

[6] P. Thomas-Vielma, A. Cervera, B. Levenfeld, A. Varez, Production of alumina parts by powder injection molding with a binder system based on high density polyethylene, J. Eur. Ceram. Soc. 28 (2008) 763-771

[7] Z. Y. Liu, N. H. Loh, S. B. Tor, K. A. Khor, Y. Murakoshi, R. Maeda, Binder system for micropowder injection molding, Materials Letters 48 (2001) 31-38

[8] M. N. Seerane, H. K. Chikwanda, W. Focke, R. Machaka, Investigation of the powder loading of gas-atomized Ti6Al4V powder using an 'in-house' binder for metal injection moulding, Advanced Metals Initiative: Precious Metals 2013, The Southern African Institute of Mining and Metallurgy

[9] K. S. Hwang, H. K. Lin, S. C. Lee, Thermal, Solvent, and Vacuum Debinding Mechanisms of PIM Compacts, Mater. Manufac. Process. 12 (1997) 593-608

[10] J. Cheng, L. Wan, Y. Cai, J. Zhu, P. Song, J. Dong, Fabrication of W-20wt.\%Cu alloys by powder injection molding, J. Mater. Process. Technol. 210 (2010) 137-142

[11] F. H. Becker, Debinding process- physical and chemical conclusions and their practical realisations, Riedhammer GmbH, Klingenhofstrasse 72, 90411 Nürnberg, pp. 6 